\title{
Drilled Core Specimen Testing Method for Determination of Tensile Strength Values of Rock Materials
}

\author{
Eren Komurlu ${ }^{1 *}$, Serhat Demir ${ }^{2}$ \\ ${ }^{1}$ Department of Civil Engineering, \\ Faculty of Engineering, \\ Giresun University \\ 28200, Güre, Giresun, Turkey, \\ 2 Department of Civil Engineering, \\ Faculty of Engineering, \\ Karadeniz Technical University, \\ 61080, Ortahisar, Trabzon, Turkey \\ * Corresponding author, e-mail: eren.komurlu@giresun.edu.tr
}

Received: 13 May 2018, Accepted: 17 August 2018, Published online: 14 September 2018

\begin{abstract}
In this study, a new direct tensile strength determination method of drilled core specimen testing was investigated with numerical and experimental studies. Effect of different drill diameters of holes of the rock specimens was analysed to assess the ideal drill-hole design. The aim of drilling process is decreasing the failure load and stress concentration at the adhesive part to prevent invalid failures. Drilled specimens were determined to fail due to the start of cracking under the condition of uniaxial tensile stress distribution at sidewalls of holes. It was found that drill bits with the diameter of $11 \mathrm{~mm}$ is usable for a practical specimen drilling process to make a significant decrease in the failure load of the core specimens with the NX size ( $\cong 54 \mathrm{~mm}$ ) diameter. According to the results obtained from numerical and experimental analyses, an equation was suggested to determine uniaxial tensile strength values of drilled core specimens with the hole diameter of $11 \mathrm{~mm}$.
\end{abstract}

Keywords

tensile strength of rock materials, rock testing, experimental rock mechanics, finite element analyses

\section{Introduction}

Because of some limitations and lackings of the direct tensile strength test method, some indirect tensile strength tests like splitting (Brazilian) method are widely used in rock mechanics laboratories. Although various indirect test methods have been developed due to the necessity of practical testing facility, results obtained from indirect test methods are doubtful as a result of not ability to be considered as uniaxial tensile strength values [1-6]. The most important problem of the direct tensile strength (DTS) test method can be stated as adhesive part failure instead of that in the rock specimen. The invalid failure of adhesive part can be many times seen especially for high strength rock materials. Besides of the use of adhesives for loading core specimens, different DTS test methods like using dog-bone shaped rock specimens have been developed for effective holding, but they are not popular because of impractical specimen preparation works [7-9].
The motivation of this study is the need for practical DTS test specimen preparation and eliminating the invalid adhesive failure in case of using standard core specimens.

To decrease stress concentration at the adhesion part for preventing invalid failures, a new DTS test method of using drilled core specimens was investigated in this study. For the aim of determination of ideal rock failure resulting from the crack initiation under the control of uniaxial tensile stresses, effect of different diameters of holes drilled at the middle length of the core specimens was analysed by numerical modelling. In addition, an experimental study was carried out in this study to check findings from the numerical study.

To decide an ideal drill design, two important criteria of drilling practicality and making a significant decrease in failure load in comparison with that of the undrilled (standard) specimens were focussed on. As another topic, 
validity of drilled specimen testing method for determination of the uniaxial tensile strength (UTS) values was investigated carrying out a series of stress distribution analyses. A drill design should supply valid failures under the control of uniaxial tensile stresses to be assessed as ideal. In case of having a biaxial or triaxial stress distribution, major principal stresses which make the failure under tension differ from UTS values. To have similar major principal stress values at the start of failure with that of the UTS, minor principal stresses should be low enough to be practically negligible [10-12].

\section{Numerical Analyses}

\subsection{Methodology}

To better understand the stress distributions around drill holes with different diameters, Finite Element Analyses (FEM) were performed by using the ANSYS software which contain special elements and material models for brittle materials like rocks. In the numerical study, variations of failure load with the change of the drill design were investigated and failure of the models was assessed whether it is valid under the control of the uniaxial tensile stress concentration.

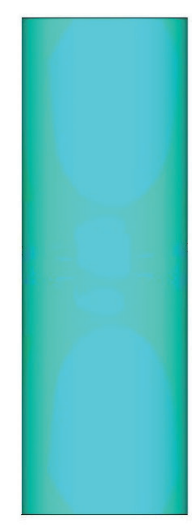

$d=0 \mathrm{~mm}$

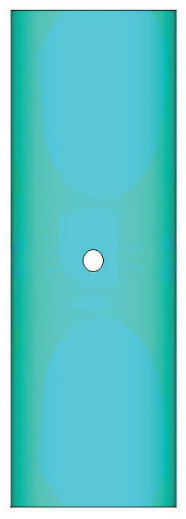

$d=6 \mathrm{~mm}$

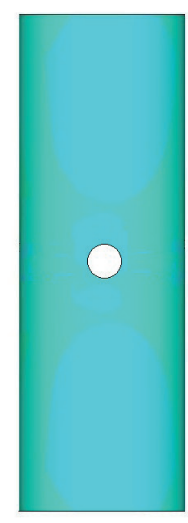

$d=11 \mathrm{~mm}$

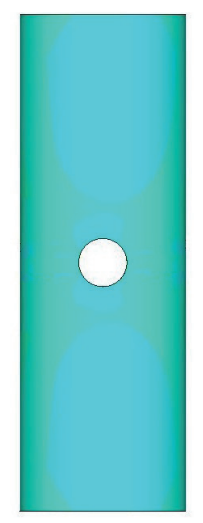

$d=16 \mathrm{~mm}$
Fig. 1 Different drill designs

Table 1 Material properties in numerical analyses (UCS: Uniaxial compressive strength, UTS: Uniaxial tensile strength, $E$ : Modulus of Elasticity, $v$ : Poisson's ratio)

\begin{tabular}{lcccc}
\hline Material model & UCS $(\mathrm{MPa})$ & UTS $(\mathrm{MPa})$ & $E(\mathrm{GPa})$ & $v$ \\
\hline Material 1 & 60 & 6 & 30 & 0.3 \\
Material 2 & 60 & 6 & 45 & 0.3 \\
Material 3 & 60 & 6 & 15 & 0.3 \\
Material 4 & 60 & 6 & 30 & 0.4 \\
Material 5 & 60 & 6 & 30 & 0.2 \\
\hline
\end{tabular}

As seen in Fig. 1, different models with different drill diameters $(d)$ of $6 \mathrm{~mm}, 11 \mathrm{~mm}$ and $16 \mathrm{~mm}$ and models without a drill hole were analysed to investigate the drill hole design effect on the stress distribution and the strength test results. Considering a widely used core driller diameter of NX size, the core specimens were modelled to have the diameter of $54 \mathrm{~mm}$. As parallel to the suggestions of International Society for Rock Mechanics and Rock Engineering (ISRM), length to diameter ratio of the models were 3 [13]. Material properties as input values for the rock models are given in Table 1. Different materials were modelled in the analyses to investigate whether a hole drilling design has same effect in case of having different material properties like Poisson's ratio and modulus of elasticity.

Eight-node solid brick elements (Solid65) were used for three-dimensional modelling of rocks, which have the capability of cracking in tension, crushing in compression, plastic deformation, and three degrees of freedom at each node, including transition in the nodal $\mathrm{x}, \mathrm{y}$, and $\mathrm{z}$ directions. Materials were modelled by considering the linear and non-linear properties defining the behaviors of the elements. The modelled material was defined as linear elastic material until the crack initiation occurs. After the crack initiation, change of the normal and shear stresses has been re-calculated by the program. The re-calculated shear stresses were transferred by the plasticity due to the generated open and closed cracks. The shear transfer coefficient was accepted as 0.3 and 0.1 for closed and open cracks, respectively. In addition, the stiffness reduction factor considered as 0.6 to define plasticity had an important role in the behavior of cracked elements. These models predicted the failure of brittle materials according to the WillamWarnke failure criteria used for concrete, rocks and other cohesive-frictional materials such as ceramics [14]. A static analysis was performed for each of the models, and the full Newton-Raphson method was used for non-linear

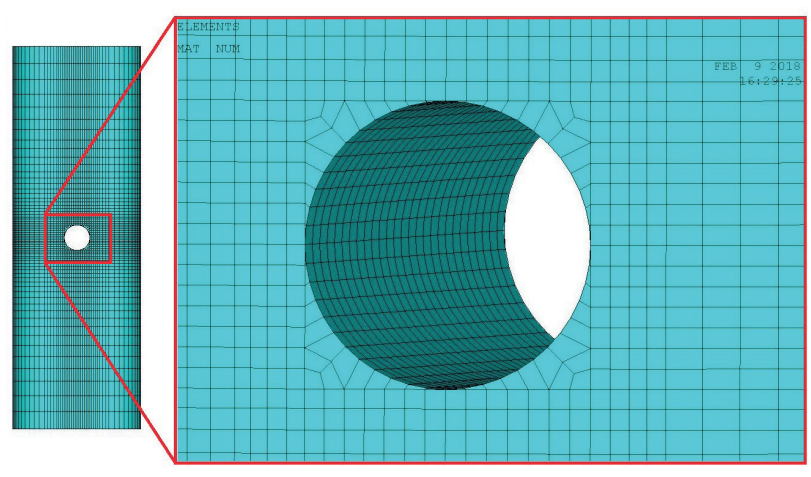

Fig. 2 Meshing around the hole with the diameter of $11 \mathrm{~mm}$ 


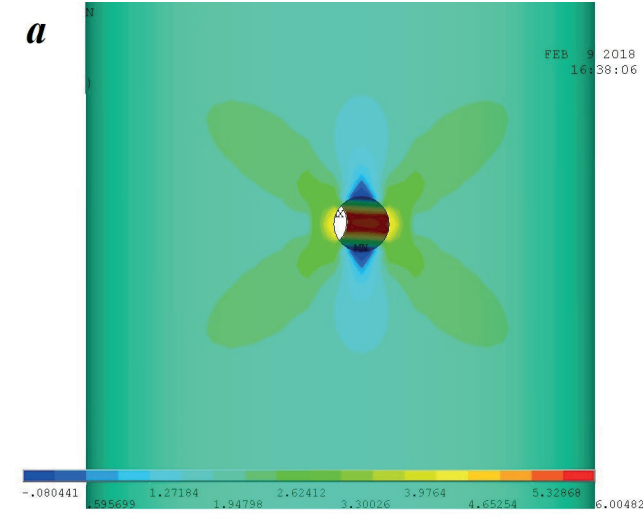

(a)

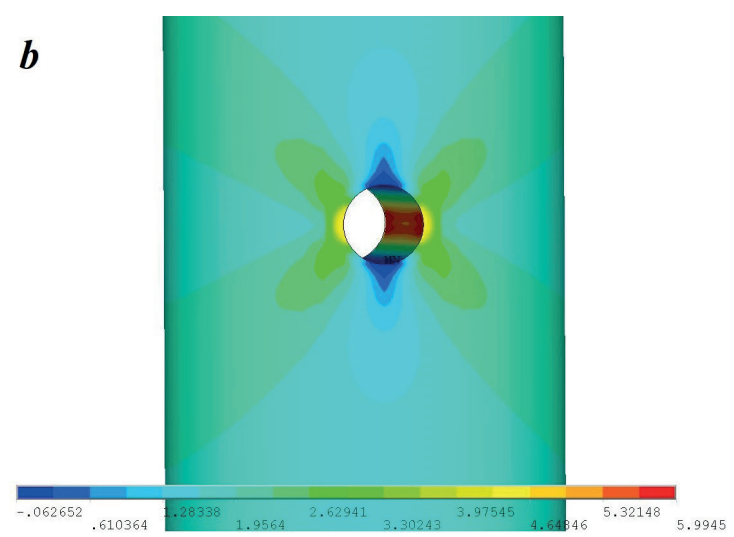

(b)

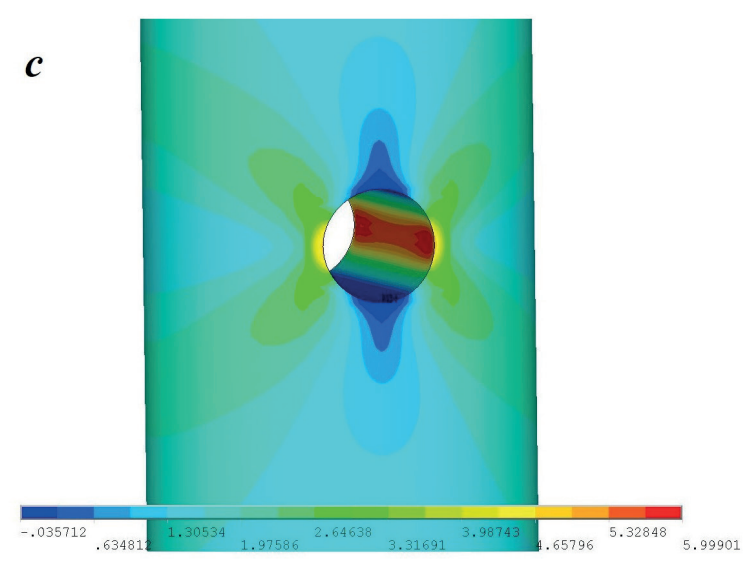

(c)

Fig. 3 Stress distribution in the Material 1 models with different drill diameters of $6 \mathrm{~mm} \mathrm{(a),11} \mathrm{mm}(\mathrm{b})$ and $16 \mathrm{~mm}$ (c)

analysis. For displacement-controlled loading, loads were divided into multiple sub-steps until the total load was achieved. Stress distributions and cracking mechanisms for all specimen models were plotted for comparison with the experimental results.

The mesh length in the rock models was chosen to be 1 $\mathrm{mm}$ around drill holes where is the most critical part for the start of failure and increase from $1 \mathrm{~mm}$ depending on the distance from the hole. Various finite element models
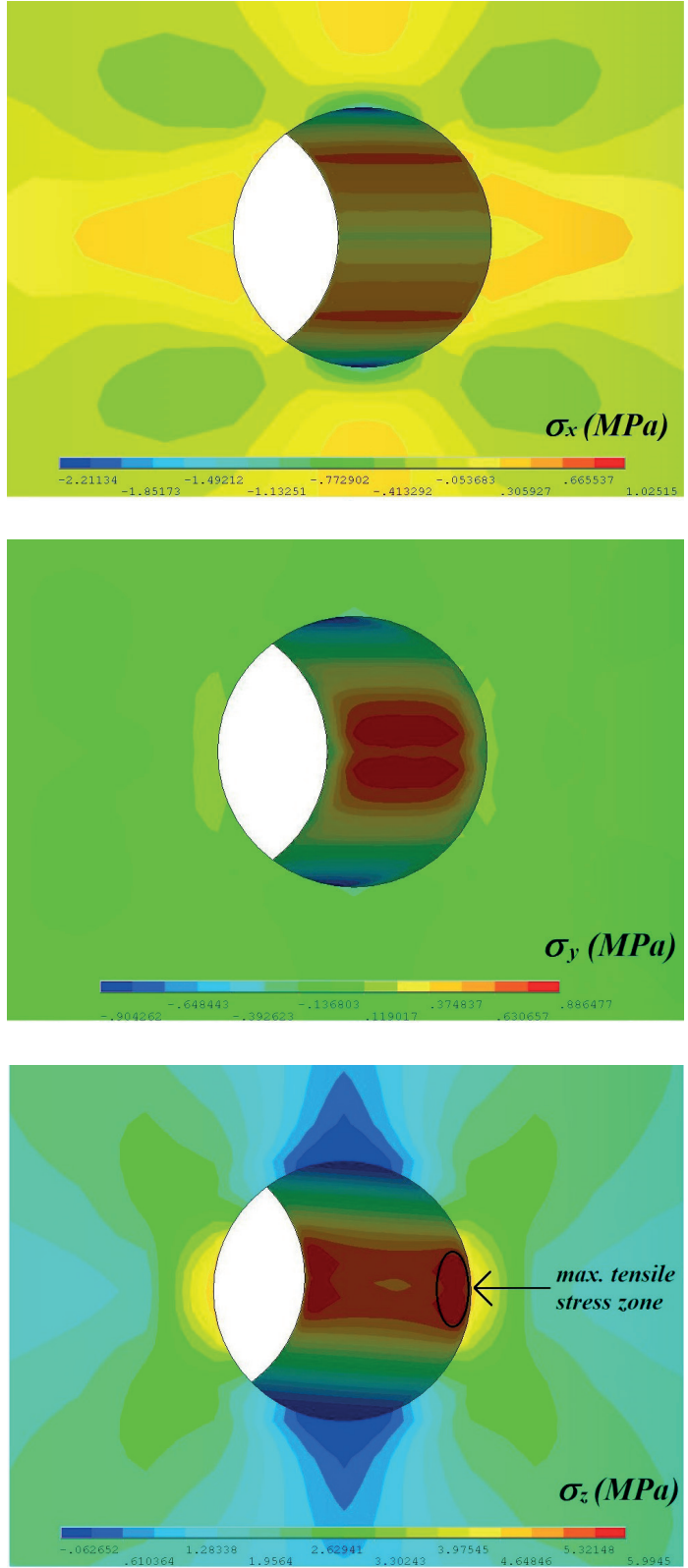

Fig. 4 Stresses in $\mathrm{x}$, $\mathrm{y}$ and $\mathrm{z}$ directions $(\mathrm{d}=11 \mathrm{~mm}$, Material 1$)$

with different meshes were analyzed in an effort to ensure that the selected mesh is dense enough to provide sufficient solution convergence. A figure for the meshing condition is given in Fig. 2. In this numerical analysis, the direct tensile strength (DTS) test was simulated applying tensile load from up and down side parallel surfaces of core specimen models.

\subsection{Results}

According to the results obtained from the numerical analyses, maximum tensile stresses were determined to be induced at the side walls of drill holes as seen in Figs. 3 and 4. At location of the maximum tensile stress, stress 
distribution conditions can be assessed to be practically uniaxial. For all the models, specimens were failed as the stresses at the side walls reach to be quite close to the uniaxial tensile strength value of $6 \mathrm{MPa}$. Therefore, it was confirmed by the numerical models that the core specimens with drilled holes can supply the ability of uniaxial tensile strength value determination.

With an increase in drill-hole diameter value, failure load was found to decrease. The lowest value of the failure load was obtained from the models with drill diameter of $16 \mathrm{~mm}$ (Table 2). Drill holes with diameters of $6 \mathrm{~mm}$, $11 \mathrm{~mm}$ and $16 \mathrm{~mm}$ made decreases of $33 \%, 40 \%$ and $49 \%$ in failure loads, respectively. As a result of decrease in the failure load, the possibility of invalid failure at the adhesive part in the DTS test also decreases. Although the drill hole with the diameter of $16 \mathrm{~mm}$ was found to be the most advantageous in terms of having low failure loads, stress distribution details for further material models were carried out for the drill-hole diameter of $11 \mathrm{~mm}$, considering the drilling practicality. Stress distribution details for different material models are given in Table 3. All the material models confirmed the relation between failure load values of undrilled and drilled specimens, which is given in Eq. (1) and Eq. (2).

$F_{11} \cong 0.6 F_{u d}$,

$U T S=F_{u d} / A \cong\left(F_{11} / 0.6\right) / A$,

where UTS is uniaxial tensile strength $(\mathrm{MPa}), F_{11}$ is failure load of specimens with the drill hole diameter $(d)$ of $11 \mathrm{~mm}, F_{u d}$ is failure load of undrilled (standard) specimen $(\mathrm{kN}), A$ is cross-section area of undrilled part of the core specimen $\left(\mathrm{cm}^{2}\right)$.

The tensile stress values at side walls were found vary along drill holes. As seen in Fig. 4, the maximum tensile stresses were determined to be induced near the outside of the holes. Therefore, it should be noted herein that the triaxial stress distribution given in Table 3 includes major, intermediate and minor stress values at the maximum tensile stress location near the outside of the hole, which is the critical location for the start of cracking.

\section{Experimental Study}

\subsection{Materials and Methods}

A series of tensile strength tests was applied on limestone, andesite, basalt and siltstone type four different rock materials. To prepare rock core specimens, a core cutter with the inner diameter NX size (54.7 mm) was used. According to ISRM suggestions, all of the rock core specimens were cut to have same length to diameter ratio of 3 by using sawing machines [10]. As given in Fig. 5, rock core specimens were drilled using $11 \mathrm{~mm}$ diameter bit of a stand driller machine. Holes were vertically drilled through the diameter of the circular cross-section at the middle length of core specimens. The rock samples were selected carefully and the core samples were taken for the experiments. After visual observations, core samples having no fractures, cracks, fill joints etc. were chosen and prepared to use in tensile strength testing. The undrilled specimens were also tested in the experimental study to investigate whether relation between the results obtained with drilled specimens and standard specimens is parallel with those obtained from the numerical analyses. Using a strong epoxy based adhesive, rock specimens were glued to steel caps which had been manufactured to be held by tension test equipment. As parallel to the ISRM suggestion, the loading rate was chosen to be $0.2 \mathrm{kN} /$ sec for both standard (undrilled) and drilled tensile strength test specimens. Direct tensile strength (DTS) testing and some failed specimens are shown in Fig. 6.

Table 2 Failure loads of models with different drill diameters (Material 1)

\begin{tabular}{lc}
\hline Drill diameter & Failure load $(\mathrm{kN})$ \\
\hline Undrilled & 13.06 \\
$d: 6 \mathrm{~mm}$ & 8.79 \\
$d: 11 \mathrm{~mm}$ & 7.82 \\
$d: 16 \mathrm{~mm}$ & 6.64 \\
\hline
\end{tabular}

Table 3 Failure loads and stress distribution details for different material models $(d: 11 \mathrm{~mm})$

\begin{tabular}{|c|c|c|c|c|c|}
\hline Material Model & $\begin{array}{l}\text { Failure loads } \\
\qquad(\mathrm{kN})\end{array}$ & $\begin{array}{l}\text { Max. tension } \\
\text { location }\end{array}$ & $\begin{array}{c}\text { Major principal stress } \\
(\mathrm{MPa}) \\
\sigma_{1}\left(\sigma_{\mathrm{z}}\right)\end{array}$ & $\begin{array}{c}\text { Intermediate principal } \\
\text { stress }(\mathrm{MPa}) \\
\sigma_{2}\left(\sigma_{\mathrm{y}}\right)\end{array}$ & $\begin{array}{c}\text { Minor principal stress } \\
(\mathrm{MPa}), \\
\sigma_{3}\left(\sigma_{\mathrm{x}}\right)\end{array}$ \\
\hline Material 1 & 7.82 & Sidewalls & 5.99 & 0.23 & -0.18 \\
\hline Material 2 & 7.84 & Sidewalls & 5.99 & 0.23 & -0.18 \\
\hline Material 3 & 7.84 & Sidewalls & 5.97 & 0.24 & -0.21 \\
\hline Material 4 & 7.73 & Sidewalls & 6.01 & 0.29 & -0.22 \\
\hline Material 5 & 7.79 & Sidewalls & 5.95 & 0.15 & -0.20 \\
\hline
\end{tabular}




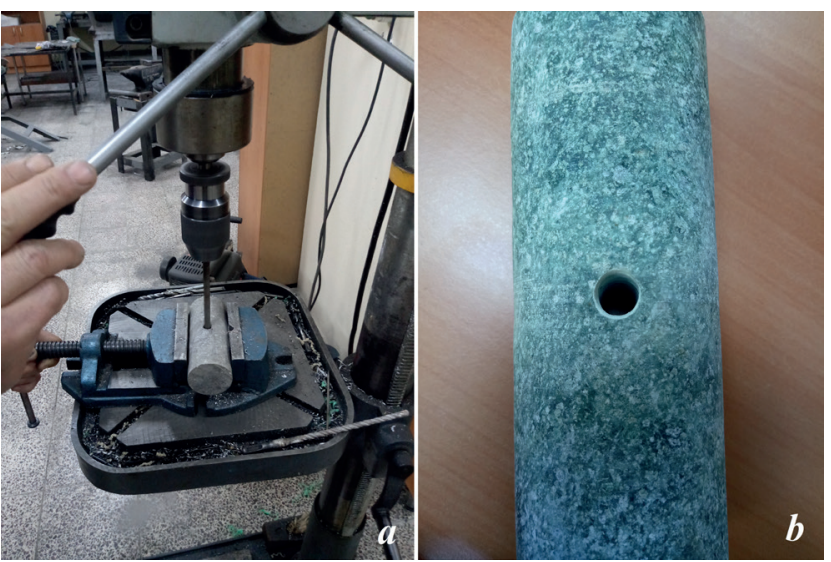

Fig. 5 a) Rock core specimen drilling, b) a drilled specimen

\subsection{Results}

As same in the observations from numerical analyses, failure of drilled specimens initiated at the side walls of the holes where are the location for the maximum tensile stress inducing. Drilled specimens were divided into two, through the sidewalls of the drill holes (Fig. 6). Failure loads obtained from the tensile strength test are given in Table 4. Strength values of standard (undrilled) specimens of basalt type rock material could not be determined under the conventional test method, because of having failure at the adhesive part instead of rock material. On the other hand, strength values of drilled basalt specimens could be calculated as a result of the valid failure of rock material. The results of this study confirm that higher strength rock materials can be tested with the new method of drilled
Table 4 Failure loads obtained from tensile strength tests (IF: Invalid failure, S.D.: Standard deviation, S.N.: Specimen number)

\begin{tabular}{lccc}
\hline Specimen Type & Failure load $(\mathrm{kN})$ & S.N. & S.D. $(\mathrm{kN})$ \\
\hline Limestone (undrilled) & 7.28 & 3 & 0.24 \\
Limestone $(d: 11 \mathrm{~mm})$ & 4.73 & 3 & 0.30 \\
Andesite (undrilled) & 8.55 & 3 & 0.21 \\
Andesite $(d: 11 \mathrm{~mm})$ & 5.30 & 3 & 0.29 \\
Siltstone (undrilled) & 6.64 & 3 & 0.33 \\
Siltstone $(d: 11 \mathrm{~mm})$ & 4.27 & 3 & 0.28 \\
Basalt $($ undrilled) & IF & 3 & - \\
Basalt $(d: 11 \mathrm{~mm})$ & 8.13 & 3 & 0.37 \\
\hline
\end{tabular}

Table 5 Relation between failure loads of drilled and undrilled specimens $\left(F_{11}\right.$ : failure load of specimens with the drill hole diameter of $11 \mathrm{~mm}, F_{u d}$ : failure load of undrilled specimen)

\begin{tabular}{lc}
\hline Rock Type & $F_{11} / F_{u d}$ \\
\hline Limestone & 0.65 \\
Andesite & 0.62 \\
Siltstone & 0.64 \\
Basalt & - \\
\hline
\end{tabular}

specimen usage in comparison with the undrilled specimen testing method. As seen from Eq. (1) derived in accordance with the numerical analyses and Table 5 including ratios between failure loads of drilled and standard (undrilled) specimens, experimental results were parallel to those obtained from the numerical analyses. Thus, the use of Eq. (2) for calculating tensile strength values of drilled core specimens was confirmed by the experimental results.
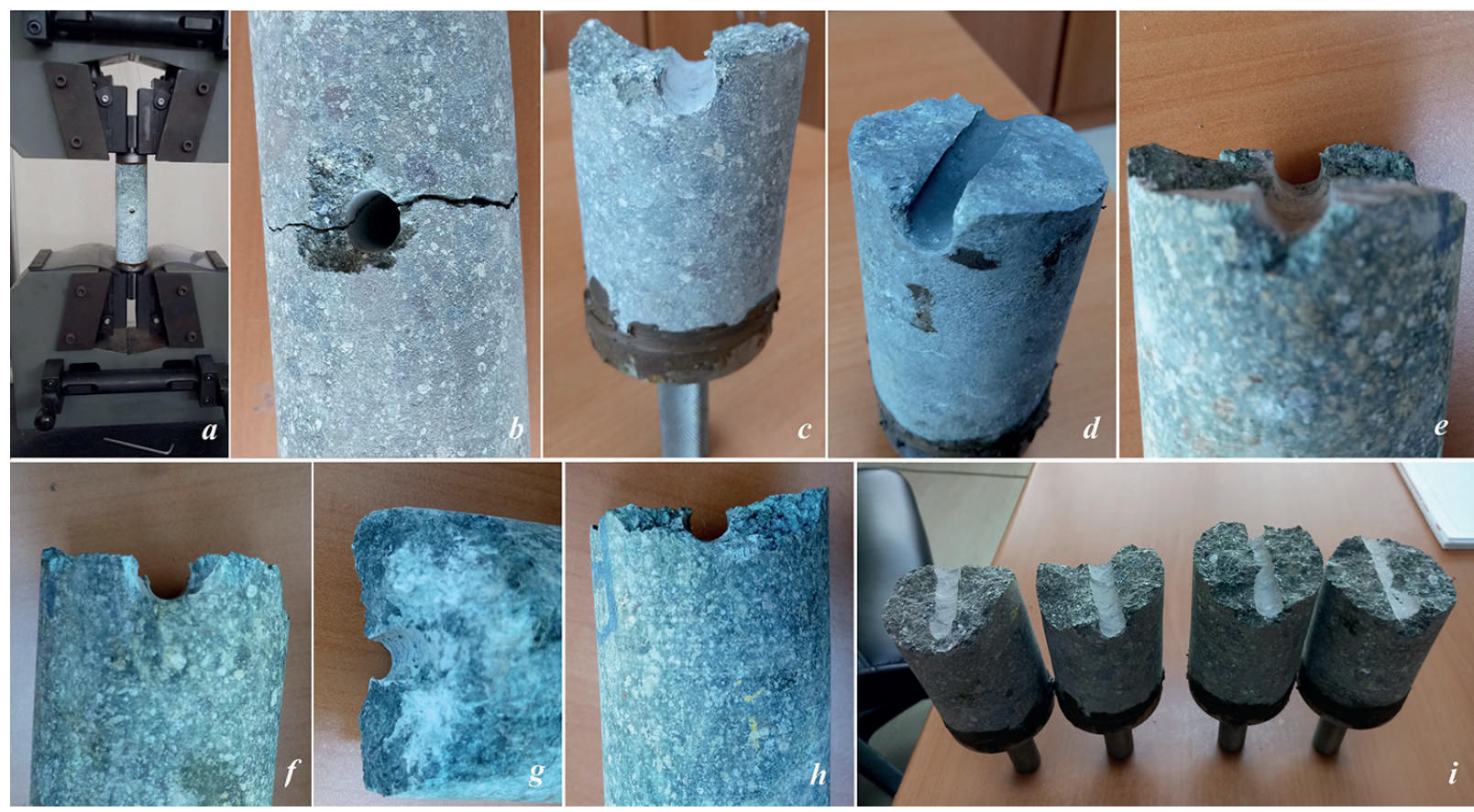

Fig. 6 a) Direct tensile strength test, b-i) drilled specimen failure 


\section{Discussions and conclusions}

The adhesive part failure problem is one of the most important problems for limitation of the use of direct tensile strength (DTS) testing method and making indirect methods like the Brazilian (splitting) tensile strength test popular [15-17]. As a result of the significant decrease in failure loads, the adhesive part failure problem was found possible to be eliminated by an easy specimen preparation step of drilling. It should be noted herein that the hole with the diameter of $11 \mathrm{~mm}$ was assessed to be practical to be made in one step drilling. A duration of several seconds was enough from start to end of the drilling process of a specimen. In case of making higher drill hole diameters than $11 \mathrm{~mm}$, more than one drilling steps with increasing bit diameters may be crucial to prevent rock cracking while specimen preparation. On this topic, new studies will be a significant guide of further investigations.

Shortly, it can be stated that drill bits with the diameter of $11 \mathrm{~mm}$ was assessed to be usable for a practical specimen drilling process to make a significant decrease in the failure load. According to the results obtained from both numerical and experimental studies, use of Eq. (2) is suggested to determine UTS values of rock materials in the case of $11 \mathrm{~mm}$ drill diameter, NX size rock core diameter and specimen length to diameter ratio of 3. Since stress distribution in the core specimens varies with the change of geometry and size parameters, the findings of this study should be considered for only the relevant case written above [18-20]. The hole drilling location is another important point that can make a significant change in the stress distribution. To make a valid failure for the use of Eq. (2), the hole should be drilled at the middle of the specimen length and through the diameter of circular cross-section of the rock core specimens without a deviation.

There is a three dimensional stress distribution at sidewalls of drill holes which are the critical location of the maximum tensile stress induced. Because the minor stresses are quite low and not higher than $4 \%$ of the major principal stress at the sidewalls, stress distribution can be practically considered as uniaxial for the location of the maximum tension. The major principal stress at sidewalls is tensile stress in vertical direction which is parallel to the loading direction. Additionally, two horizontal stresses which are parallel and perpendicular to drill-hole direction are intermediate and minor principal stresses at sidewalls, the location of the maximum tension. It is advantageous to have low level minor and intermediate principal stresses that can make the major principal stress values to be quite close to the uniaxial tensile strength value [21-23].

The Poisson's ratio is an effective factor making variations in induced horizontal stresses with important percentages [24-27]. As seen in Table 3, the horizontal stress was found to increase by 1.9 times with the change in Poisson's ratio from 0.2 to 0.4 . In spite of the effect of Poisson's ratio, failure loads and major principal stresses at the maximum tensile stress concentration zone were determined to be similar because of small values of intermediate and minor principal stresses in horizontal direction. Because of the low horizontal stresses at the critical part of the maximum tension in vertical direction, the material properties effect on triaxial stress distribution and major principal stress values at the failure was assessed to be negligible. Therefore, different materials with a same strength value can give practically same failure loads and strength test results calculated in accordance with Eq. (2) which was suggested for determination of uniaxial tensile strengths of the drilled rock specimens.

In conclusion, a new testing method of drilled specimen usage was assessed to be able to contribute much to the rock testing area by eliminating invalid adhesive failure problems in DTS determination. According to the results obtained from this study, new researches on the drilled core specimen testing are suggested to go further for improving the method to be a standard way to determine DTS values of rock materials.

\section{References}

[1] Komurlu, E., Kesimal, A., Demir, S. "An Experimental and Numerical Study on Determination of Indirect (Splitting) Tensile Strength of Rocks under Various Load Apparatus", Canadian Geotechnical Journal, 53(2), pp. 360-372, 2016. https://doi.org/10.1139/cgj-2014-0356

[2] Erarslan, N., Williams, D. J. "Experimental, numerical and analytical studies on tensile strength of rocks", International Journal of Rock Mechanics and Mining Sciences, 49, pp. 21-30, 2012. https://doi.org/10.1016/j.ijrmms.2011.11.007

[3] Erarslan, N., Liang, Z. Z., Williams. D. J. "Experimental and Numerical Studies on Determination of Indirect Tensile Strength of Rocks, Rock Mechanics and Rock Engineering, 45(5), pp. 739751, 2012.

https://doi.org/10.1007/s00603-011-0205-y

[4] Kourkoulis, S. K., Markides, C. F., Hemsley, J. A. "Frictional stresses at the disc-jaw interface during the standardized execution of the Brazilian disc test", Acta Mechanica, 224(2), pp. 255-268, 2013.

https://doi.org/10.1007/s00707-012-0756-3 
[5] Markides, C, F., Pazis, D. N., Kourkoulis, S. K. "The Brazilian disc under non-uniform distribution of radial pressure and friction", International Journal of Rock Mechanics and Mining Sciences, 50, pp. 47-55, 2012. https://doi.org/10.1016/j.ijrmms.2011.12.012

[6] Sarfarazi, V., Schubert, W. "Numerical Simulation of Tensile Failure of Concrete in Direct, Flexural, Double Punch Tensile and Ring Tests", Periodica Polytechnica Civil Engineering, 61(2), pp. 176$183,2017$.

https://doi.org/10.3311/PPci.9028

[7] Fuenkajorn, K., Klanphumeesri, S. "Laboratory Determination of Direct Tensile Strength and Deformability of Intact Rocks", Geotechnical Testing Journal, 34(1), pp. 97-102, 2011.

https://doi.org/10.1520/GTJ103134

[8] Langford, J. C., Perras, M. A. "Obtaining reliable estimates of intact tensile strength", In: Proceedings of 48th US Rock Mechanics/ Geomechanics Symposium, Minneapolis, Minnesota, USA, 2014, pp. 1016-1023.

[9] Mogi, K. "Experimental Rock Mechanics", Taylor and Francis Group, Leiden, Netherlands, 2007.

[10] Komurlu, E., Kesimal, A., Demir, A. D. "Dogbone shaped specimen testing method to evaluate tensile strength of rock materials", Geomechanics and Engineering, 12(6), pp. 883-898, 2017. https://doi.org/10.12989/gae.2017.12.6.883

[11] Unlu, T., Yilmaz, O. "Development of a New Push-Pull Direct Tensile Strength Testing Apparatus (PPTA)", Geotechnical Testing Journal, 37(1), pp. 60-70, 2014. https://doi.org/10.1520/GTJ20130040

[12] Franklin, J. A. "Triaxial Strength of Rock Materials", Rock Mechanics and Rock Engineering, 3(2), pp. 86-98, 1971. https://doi.org/10.1007/BF01239628

[13] Ulusay, R., Hudson, J. A. (eds.) "The Complete ISRM Suggested Methods for Rock Characterization, Testing and Monitoring: 1974 2006", 1st ed., ISRM Turkish National Group, Ankara, Turkey, 2007.

[14] Willam, K. J., Warnke, E. P. "Constitutive model for the triaxial behaviour of concrete", presented at Seminar on Concrete Structures Subjected to Triaxial Stresses, Bergamo, Italy, May, 17-19, 1974. https://doi.org/10.5169/seals-17526

[15] Komurlu, E., Kesimal, A. "Evaluation of Indirect Tensile Strength of Rocks using Different Types of Jaws", Rock Mechanics and Rock Engineering, 48(4), pp. 1723-1730, 2015.

https://doi.org/10.1007/s00603-014-0644-3

[16] Komurlu, E., Kesimal, A., Demir, S. "Determination of Indirect (Splitting) Tensile Strength of Cemented Paste Backfill Materials", Geomechanics and Engineering, 10(6), pp. 775-791, 2016. https://doi.org/10.12989/gae.2016.10.6.775

[17] Perras, M. A., Diederichs, M. S."A Review of the Tensile Strength of Rock: Concepts and Testing", Geotechnical and Geological Engineering, 32(2), pp. 525-546, 2014. https://doi.org/10.1007/s10706-014-9732-0

[18] Komurlu, E., Kesimal, A., Durmus Demir, A. "A Numerical Study for Determining Ideal Size and Geometry of Dog bone shaped direct tensile strength test specimens", In: European Rock Mechanics Symposium 2016 (EUROCK 2016), Cappadocia, Turkey, 2016, pp. 325-330.
[19] Tufekci, K., Demirdag, S., Sengun, N., Altindag R., Akbay, D. "A new design test apparatus for determining direct tensile strength of rocks", In: Rock Mechanics and Rock Engineering: From the Past to the Future, Cappadocia, Turkey, 2016.

[20] Unlu, T., Yilmaz, O. "A new method developed for determining direct tensile strength of intact rock materials", In: ROCKMEC'2014 - XIth Regional Rock Mechanics Symposium, Afyonkarahisar, Turkey, 2014, pp. 97-106.

[21] Coviello, A., Lagioia, R., Nova R. "On the Measurement of the Tensile Strength of Soft Rocks", Rock Mechanics and Rock Engineering, 38(4), 251-273, 2005. https://doi.org/10.1007/s00603-005-0054-7

[22] Bineshian, H., Ghazvinian, A., Bineshian, Z. "Comprehensive compressive- tensile strength criterion for intact rock", Journal of Rock Mechanics and Geotechnical Engineering, 4(2), 140-148, 2012.

https://doi.org/10.3724/SP.J.1235.2012.00140

[23] You, M. "Strength criterion for rocks under compressive-tensile stresses and its application", Journal of Rock Mechanics and Geotechnical Engineering, 7(4), pp. 434-439, 2015. https://doi.org/10.1016/j.jrmge.2015.05.002

[24] Gercek, H. "Poisson's ratio values for rocks", International Journal of Rock Mechanics and Mining Sciences, 44(1), pp. 1-13, 2007. https://doi.org/10.1016/j.ijrmms.2006.04.011

[25] Gercek, H. "Classification of rocks based on their Poisson's ratio", presented at ROCKMEC'2004 - VIIth Regional Rock Mechanics Symposium, Sivas, Türkiye, October, 21-22. 2004.

[26] Unlu T, Gerçek H. "Effect of Poisson's ratio on the normalized radial displacements occurring around the face of a circular tunnel", Tunnelling and Underground Space Technology, 18(5), pp. 547-553, 2003. https://doi.org/10.1016/S0886-7798(03)00086-5

[27] Komurlu, E., Kesimal, A., Hasanpour, R. "In situ horizontal stress effect on plastic zone around circular underground openings excavated in elastic zones", Geomechanics and Engineering, 8(6), pp. 783-799, 2015. https://doi.org/10.12989/gae.2015.8.6.783 